\title{
The Effect of North American Free Trade Agreement (NAFTA): Ten Years Later
}

Miranda M. Zhang, (E-mail: zhang_mm@mercer.edu), Mercer University Tyler T. Yu, (E-mail: yu_tl@mercer.edu), Mercer University

\begin{abstract}
This paper examines the economic impact of the North American Free Trade Agreement (NAFTA) on international trade among the three member countries - Canada, Mexico and the United States, in the past ten years. Through regression techniques, estimated volume and the predicted trend for exports among the countries are compared with the actual observations. The empirical results indicate that NAFTA did achieve the desired goal of increasing trade among their member countries. The actual trade volume is greater than what the estimated trade volume would have been without NAFTA. Although all the member countries have seen their exports increased, the volumes vary among the three, with Mexico being the largest beneficiary.
\end{abstract}

\section{Introduction}

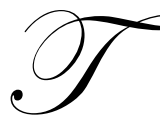

he year 2003 marks the 10th anniversary of the establishment of the North American Free Trade Agreement (NAFTA). Under this agreement, a free-trade bloc was created in which the three member countries, Canada, Mexico, and the United States have removed trade barriers among themselves but keep their separate national barriers against trade with the rest of the world. The rationale behind such a trade bloc agreement is to increase trade among the member countries, which will in turn raise world economic welfare.

Ten years have passed by since the NAFTA went into effect. It is important to know and if feasible, to measure quantitatively the effects of NAFTA on the economic welfare of the member countries. The purpose of this study is to empirically examine the economic impact of NAFTA on international trade among the three member countries. Specifically, regression techniques will be used to estimate trend lines for exports among the three member countries. Then, the predicted exports for the initial eight-years of NAFTA era will be compared with the actual observations of exports for the same period for the three member countries. Finally, some conclusions will be drawn from the study.

NAFTA has generated one of the most heated debates in the 1990s and as a result of that, there has been plethora of research regarding various issues pertinent to the agreement. Free trade advocates argued that open markets would create opportunities for businesses of all member countries, which would then stimulate their domestic economic growth. Protectionists stated that domestic jobs would be lost to cheaper foreign labor. To certain degree, both have occurred. However, the net effect has been favorable for the United States and Mexico, while the effect is less significant for Canada. Overall, the impact of NAFTA is that it has changed the business environment within which firms operate. It has created both opportunities and threats simultaneously (Pett and Wolff, 2003).

Cavanagh and Anderson conducted a study examining, among other things, the economic effect of NAFTA on member countries' labor markets. The agreement has increased investment and trade among the member countries. In addition, the secondary effect is that increased international competition due to freer trade may have resulted in increase labor productivity during the 1990s. However, the achievement in productivity did not come without cost. For example, in Mexico, the reported 50\% increase in labor productivity was accompanied by an $11 \%$ 
slide in real manufacturing wages between 1994 to 2001. Also, the achievement was not evenly distributed in Mexico. Mexican farmers were devastated by the foreign agricultural commodities and the rural area of the country had seen a rise in poverty rate to $82 \%$, which was partially due to the fact that NAFTA opened the floodgate to cheap U.S. corn imports. In the U.S., workers have been facing the pressure of global human-resource outsourcing. U. S. employers frequently threaten to relocate their production facilities to Mexico and other low-wage countries in order to better negotiate with unions and restrain wages (Cavanagh and Anderson, 2002).

On the contrary, some researchers have found that NAFTA has had positive effect on Mexican wages. In their study, Serra and Espinosa argued that from 1994 to 1996, Mexican firms that had exported more than 80\% of their total sales paid between 58 to $67 \%$ higher wages than the average wage rate. The researchers also argued that overall, NAFTA achieved the objective of promoting trade and investment. Ten years ago, exports from Mexico were at par with those from the rest of the Latin America region. Now, Mexico's exports nearly double those of the rest of the Latin American countries combined. Equally drastic achievement has been found in terms of foreign direct investments. During the eight proceeding years before NAFTA, the average annual inflow of foreign direct investment to Mexico was approximately $\$ 3.47$ million dollars. Since then, it has exceeded $\$ 13$ billion (Serra and Espinosa, 2002).

Wall conducted a study primarily focusing on the effects of NAFTA on the geographical pattern of North American trade. The research suggests that the trade patterns and geographical outsourcing patterns have changed within the NAFTA region. Because NAFTA establishes a preferential trade area (PTA) the prosperity of this region depends on the relative sizes of trade creation and trade diversion. Companies' geographical movements within the PTA can help the organization leverage its economies of scale and be in a better position to produce more which in turn creates more trade. This drive in exports then requires more inputs from within the PTA region (Wall, 2003).

\section{Data And Models}

In order to empirically estimate the effects of NAFTA, export data were collected for the three member countries for the period from 1965 to 2001. The data were gathered from two sources: International Statistical Yearbooks by the IMF and the Statistical Abstract of the United States by the U.S. Department of Commerce. Using the data from 1965 to 1993 , the year NAFTA was established, six regression equations were estimated for exports from each of the three member countries to the other two. The result of the estimation is reported in Table 1.

Table 1: Regression equations for Exports among NAFTA Region

\begin{tabular}{|c|c|c|c|}
\hline Estimated Equation of Export & Adjusted $\mathbf{R}^{2}$ & F-Test $(\alpha=0.05)$ & t-Test $(\alpha=0.05)$ \\
\hline $\begin{array}{l}\text { U.S. Export to Canada: } \\
Y_{1}=-10480+3204.946 \mathrm{X}\end{array}$ & 0.909 & $p<0.000$ & $p<0.000$ \\
\hline $\begin{array}{l}\text { US Export to Mexico: } \\
\mathrm{Y}_{2}=-6610+1237.70 \mathrm{X}\end{array}$ & 0.786 & $p<0.000$ & $p<0.000$ \\
\hline $\begin{array}{l}\text { Canada Export to U.S.: } \\
\mathrm{Y}_{3}=-11738+43.57 \mathrm{X}\end{array}$ & 0.957 & $p<0.000$ & $p<0.000$ \\
\hline $\begin{array}{l}\text { Canada Export to Mexico: } \\
\mathrm{Y}_{4}=-7.126+8.27 \mathrm{X}\end{array}$ & 0.777 & $p<0.000$ & $p<0.000$ \\
\hline $\begin{array}{l}\text { Mexico Export to U.S.; } \\
Y_{5}=-7488+1327.50 X\end{array}$ & 0.898 & $p<0.000$ & $p<0.000$ \\
\hline $\begin{array}{l}\text { Mexico Export to Canada: } \\
Y_{6}=-275+1.628 \mathrm{X}\end{array}$ & 0.681 & $p<0.000$ & $p<0.000$ \\
\hline
\end{tabular}

The $\mathrm{Y}$ variables are exports from the member countries and the $\mathrm{X}$ variable is the time series from 1965 to 1993. As shown in Table 1, all six equations are statistically significant as confirmed by the F-tests and t-Tests. The estimated equations also have relatively high adjusted $\mathrm{R}^{2}$, which implies a good fit of the model. The positive sign 
for the coefficients of the explanatory variable $(\mathrm{X})$ is consistent with the expectation for NAFTA, meaning the general trend of exports for all three member countries is going up.

Using the estimated equations, exports from the member countries were fitted for the initial eight years of the NAFTA era from 1994 to 2001. The fitted exports were then compared with the actual observations of exports for the same period. The results were reported in Tables 2 to 4 .

Table 2: Comparison Between fitted and actual Exports from the U.S. to NAFTA

\begin{tabular}{|c|c|c|c|c|c|c|c|c|}
\hline & \multicolumn{3}{|c|}{ U.S. Export to Canada } & \multicolumn{4}{c|}{ U.S. Export to Mexico } \\
\hline Year & Fitted & Actual & Increase & $\mathbf{\%} \boldsymbol{\Delta}$ & Fitted & Actual & Increase & $\%$ $\boldsymbol{\Delta}$ \\
\hline 1994 & 85668 & 114438 & 28770 & $33.58 \%$ & 30521 & 50843 & 20322 & $66.58 \%$ \\
\hline 1995 & 88872 & 127226 & 38354 & $43.16 \%$ & 31759 & 46292 & 14533 & $45.76 \%$ \\
\hline 1996 & 92077 & 134210 & 42133 & $45.76 \%$ & 32996 & 56792 & 23796 & $72.12 \%$ \\
\hline 1997 & 95282 & 151766 & 56484 & $59.28 \%$ & 34234 & 71388 & 37154 & $108.53 \%$ \\
\hline 1998 & 98487 & 156603 & 58116 & $59.01 \%$ & 35472 & 78723 & 43251 & $121.93 \%$ \\
\hline 1999 & 101692 & 166600 & 64908 & $63.83 \%$ & 36709 & 86909 & 50200 & $136.75 \%$ \\
\hline 2000 & 104897 & 178941 & 74044 & $70.59 \%$ & 37947 & 111349 & 73402 & $193.43 \%$ \\
\hline 2001 & 108102 & 163424 & 55322 & $51.18 \%$ & 39185 & 101297 & 62112 & $158.51 \%$ \\
\hline
\end{tabular}

As shown in Table 2, comparing with the fitted data, U.S. exports to Canada and Mexico have both increased significantly during the first eight years of NAFTA era. For example, U.S. export to Canada increased somewhere between 33\% to 70\% while its export to Mexico increased even more, from $72 \%$ in 1996 to $193 \%$ in 2000 .

Canadian exports to the United States and Mexico have also increased comparing with the fitted data. The country's export to the U.S. increased between $27.68 \%$ in 1994 and $87.63 \%$ in 2002. The Canadian export to Mexico increased from $32.16 \%$ in 1994 to $131.24 \%$ in 2001.

Table 3: Comparison Between fitted and actual Exports from Canada to NAFTA

\begin{tabular}{|c|c|c|c|c|c|c|c|c|}
\hline \multirow[b]{2}{*}{ Year } & \multicolumn{4}{|c|}{ Canada Export to U.S. } & \multicolumn{4}{|c|}{ Canada Export to Mexico } \\
\hline & Fitted & Actual & Increase & $\% \Delta$ & Fitted & Actual & Increase & $\% \Delta$ \\
\hline 1994 & 100569 & 128405 & 27836 & $27.68 \%$ & 541 & 715 & 174 & $32.16 \%$ \\
\hline 1995 & 104312 & 144369 & 40057 & $38.40 \%$ & 559 & 786 & 227 & $40.61 \%$ \\
\hline 1996 & 108056 & 155892 & 47836 & $44.27 \%$ & 578 & 855 & 277 & $47.92 \%$ \\
\hline 1997 & 111800 & 168201 & 56401 & $50.45 \%$ & 596 & 916 & 320 & $53.69 \%$ \\
\hline 1998 & 115543 & 173256 & 57713 & $49.95 \%$ & 614 & 858 & 244 & $39.74 \%$ \\
\hline 1999 & 119287 & 198711 & 79424 & $66.58 \%$ & 633 & 1025 & 392 & $61.93 \%$ \\
\hline 2000 & 123030 & 230838 & 107808 & $87.63 \%$ & 651 & 1390 & 739 & $113.52 \%$ \\
\hline 2001 & 126774 & 216268 & 89494 & $70.59 \%$ & 669 & 1547 & 878 & $131.24 \%$ \\
\hline
\end{tabular}


Table 4: Comparison Between fitted and actual Exports from Mexico to NAFTA

\begin{tabular}{|l|l|l|l|l|l|l|l|l|}
\hline \multicolumn{4}{|l}{ Mexico Export to U.S. } & \multicolumn{3}{l|}{ Mexico Export to Canada } \\
\hline Year & Fitted & Actual & Increase & $\mathbf{\%} \boldsymbol{\Delta}$ & Fitted & Actual & Increase & $\% \mathbf{~} \boldsymbol{\Delta}$ \\
\hline 1994 & 32338 & 49494 & 17156 & $53.05 \%$ & 974 & 1470 & 496 & $50.92 \%$ \\
\hline 1995 & 33666 & 62101 & 28435 & $84.46 \%$ & 1015 & 1979 & 964 & $94.98 \%$ \\
\hline 1996 & 34993 & 74297 & 39304 & $112.32 \%$ & 1099 & 2170 & 1071 & $97.45 \%$ \\
\hline 1997 & 36321 & 85938 & 49617 & $136.61 \%$ & 1140 & 2157 & 1017 & $89.21 \%$ \\
\hline 1998 & 37648 & 94629 & 56981 & $151.35 \%$ & 1182 & 1521 & 339 & $28.68 \%$ \\
\hline 1999 & 38976 & 109721 & 70745 & $181.51 \%$ & 1223 & 2391 & 1168 & $95.50 \%$ \\
\hline 2000 & 40303 & 135926 & 95623 & $237.26 \%$ & 1265 & 3353 & 2088 & $165.06 \%$ \\
\hline 2001 & 41631 & 131338 & 89707 & $215.48 \%$ & 1307 & 3070 & 1763 & $134.89 \%$ \\
\hline
\end{tabular}

Among the three member countries, Mexico has demonstrated the highest percentage increases in its exports to both Canada and the United States. As shown in Table 4, Comparing with the fitted data, Mexico's export to the U. S. increased $53.05 \%$ in 1994 , , to $237.26 \%$ in 2000 . The country's export to Canada increased somewhere between $28.68 \%$ in 1998 and $165.06 \%$ in 2000 .

Figures 1 to 6 illustrate graphically the same information presented in the above tables. Once again, the curves representing actual exports are above the curves representing the fitted lines based on regression equations that we have estimated. In addition, the actual export curves seem to depart from the fitted curves asymptotically, suggesting the long run effect of NAFTA may be larger than the short run effect.

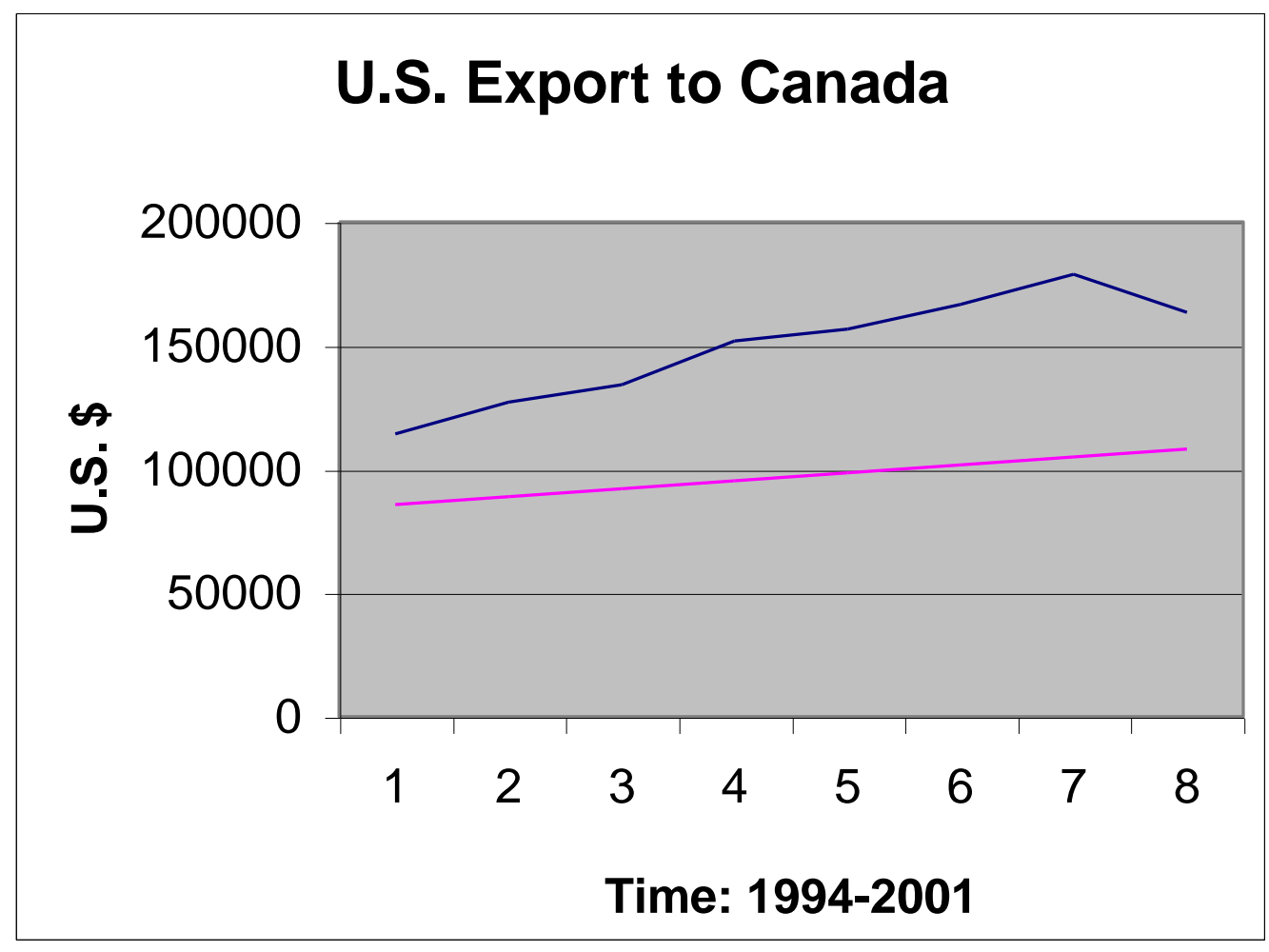



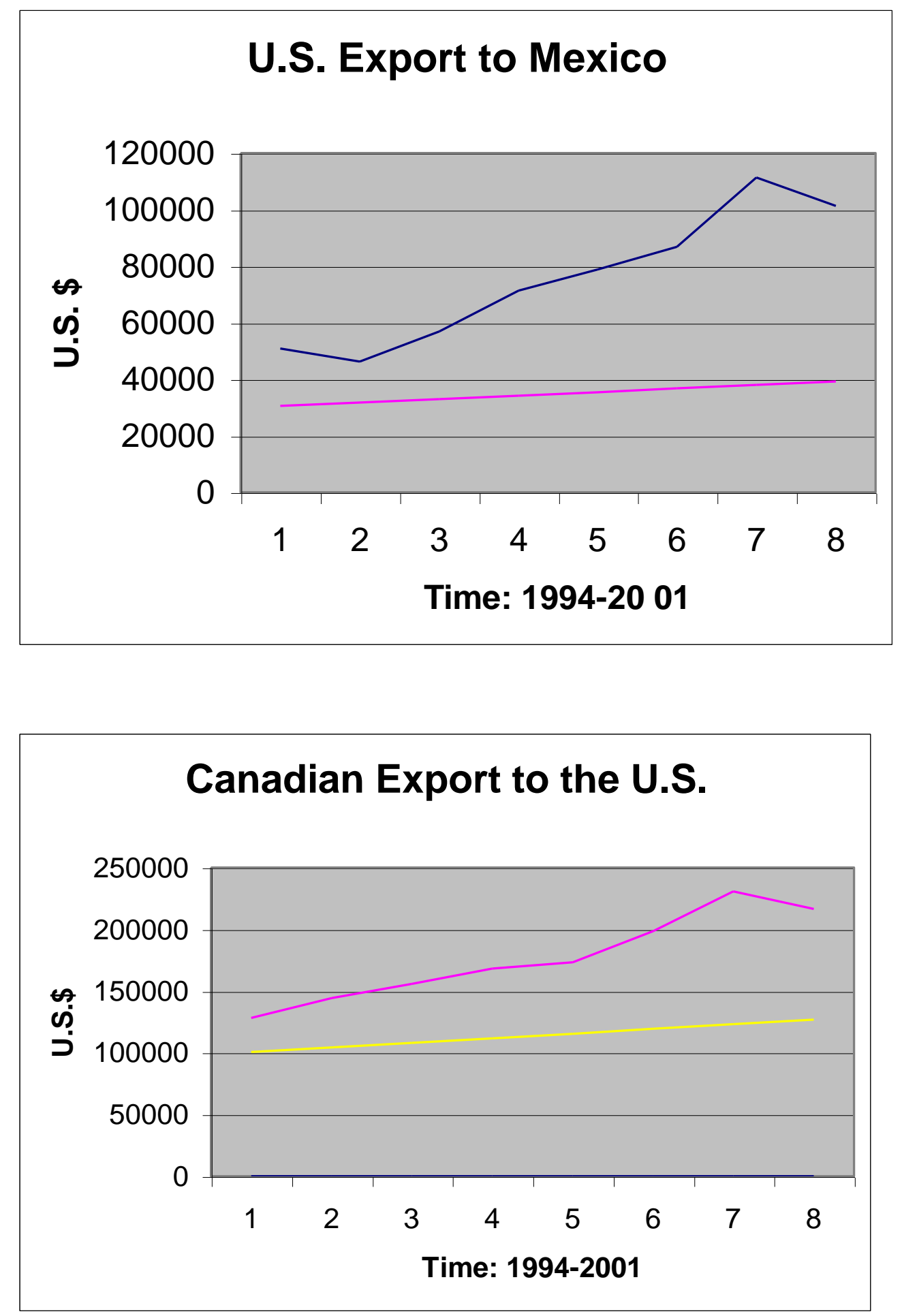


\section{Canadian Export to Mexico}

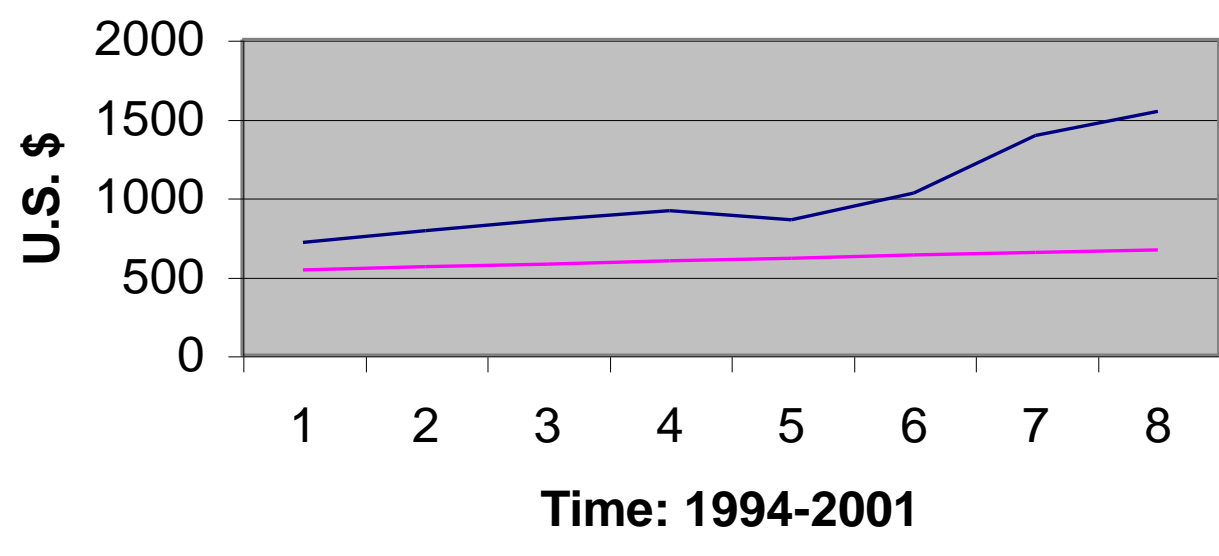

\section{Mexico's Export to U.S.}

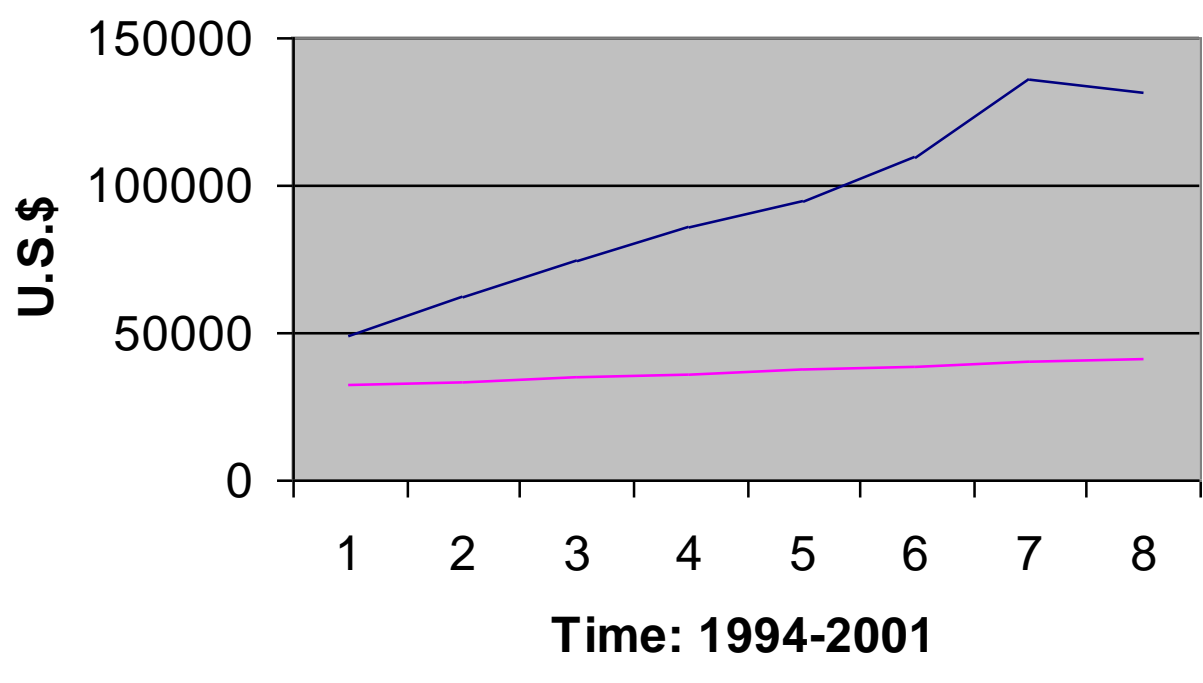




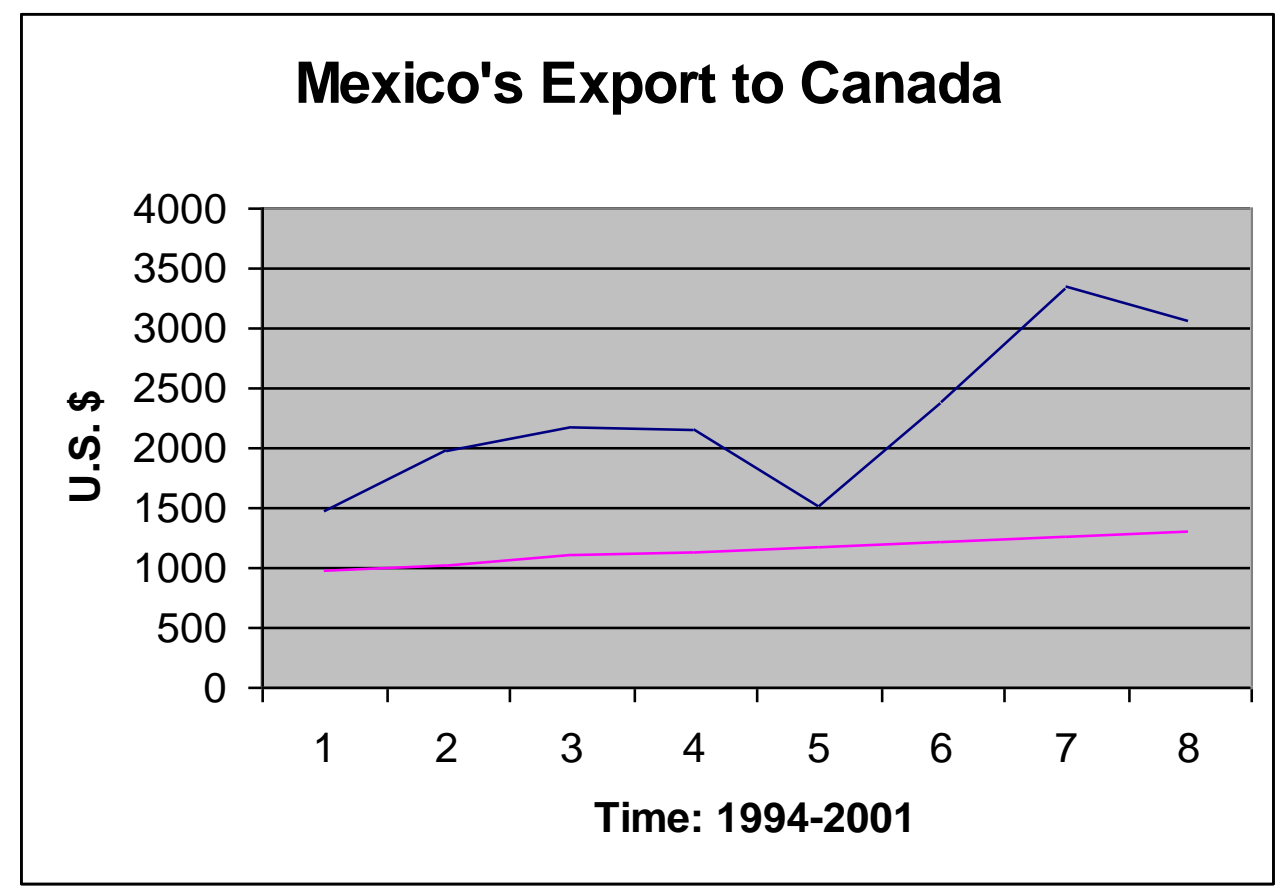

\section{Conclusions}

The empirical results of the study indicate that NAFTA did achieve the desired goal of increasing trade among the three countries. As demonstrated by the information in the table and further illustrated by the graphs, the actual trade volume, without exception, is greater than what the estimated trade volume would have been without NAFTA. Although all three member countries have seen their exports increased, the increases vary among the three member countries. It seems that Mexico has been the largest beneficiary of the three because it has achieved the highest percentage increases in exports to the other two NAFTA member countries.

The major limitation of the study is that it does not take into consideration other socioeconomic variables that might also have affected the exports. These variables may include but not limited to incomes, price indexes, exchange rates, foreign direct investments and others. In order to include these variables to conduct a more comprehensive study, a longer time period is necessary. When it is feasible, more observations in the time series will become available to facilitate a more sophisticated regression equation.

\section{References}

1. $\quad$ Cavanagh, John and Sarah Anderson, "Happily ever NAFTA?" Foreign Policy, 132, 58-65, 2002.

2. International Monetary Fund, Directory of Trade Statistics Yearbook, various issues.

3. Pett, Timothy L. and James Wolff, "Firm Characteristics and Managerial Perceptions of NAFTA: An Assessment of Export Implication for U.S.," SME's Journal of Small Business Management, Vol. 41, No. 2, 117-132, 2003.

4. US Department of Commerce, The Statistical Abstract of the United States, various issues.

5. $\quad$ Serra, Jaim and Enrique J. Espinosa, "the Proof is in the Paycheck?" Foreign Policy, 136.

6. Wall, Howard, "NAFTA and Geography of North American Trade," The Federal Reserve Bank of St. Louis, March/April 2003, 13-26. 
Notes 